\title{
ASPECTOS GENÉTICOS E BIOQUÍMICOS DE HTR1B NO TRANSTORNO DO DÉFICIT DE ATENÇÃO COM HIPERATIVIDADE
}

\author{
Augusto Sérgio Lino Gonçalves ${ }^{a}$ \\ Amália Basso de Souzab \\ Giuliana Finotti Pires ${ }^{b}$ \\ Alexandre Azenha Alves de Rezende ${ }^{b}$ \\ Luciana Karen Calábriab,
}

a Instituto de Ciências Exatas, Universidade Federal de Minas Gerais. Avenida Presidente Antônio Carlos, número 6.627, Pampulha, Belo Horizonte, Minas Gerais, Brasil, CEP 31.270-901.

b Instituto de Ciências Exatas e Naturais do Pontal, Universidade Federal de Uberlândia. Rua 20, número 1.600, Tupã,
Ituiutaba, Minas Gerais, Brasil, CEP 38.304-402.

\section{RESUMO}

O transtorno de déficit de atenção e hiperatividade (TDAH) tem origem multifatorial, geralmente revelado na infância e, em alguns casos, acompanha o indivíduo por toda a vida, apresentando sintomas de desatenção, hiperatividade e impulsividade. Dada a sua importância para a saúde pública, diversos estudos vêm sendo realizados buscando sua correlação com a expressão de genes específicos, incluindo o receptor de 5-hidroxitriptamina 1B (HTR1B) que expressa um dos receptores de serotonina e é o alvo deste estudo. Dados levantados a partir de biologia computacional revelaram que o HTR1B está localizado no cromossomo 6, em 6q14.1, e está intimamente relacionado com transtornos mentais e comportamentais. Sua expressão ocorre em diversos tecidos humanos, com destaque no córtex cerebral que é a região mais afetada no TDAH. A correlação do gene HTR1B e o TDAH é explicada pela associação do C861G (polimorfismo de nucleotídeo único) com os sintomas característicos do transtorno, revelando a suscetibilidade dos portadores deste polimorfismo. O alinhamento da sequência de HTR1B de Homo sapiens revelou alta identidade com espécies de primatas, majoritariamente chimpanzés. Dada a importância do TDAH para os indivíduos acometidos e os prejuízos adquiridos, a continuidade de estudos que relacionem o transtorno e a expressão gênica e proteica de HTR1B se faz necessária, visando avanços no diagnóstico, tratamento e prevenção.

Palavras-chave: TDAH; receptor de serotonina; biologia computacional

\footnotetext{
*Autor correspondente: Luciana Karen Calábria, Doutorado em Bioquímica, Universidade Federal de Uberlândia, Campus Pontal, Rua 20, número 1.600, Tupã, Ituiutaba, Minas Gerais, CEP 38.304-402. 34-3271-5252; Ikcalabria@ufu.br.
} 


\section{INTRODUÇÃO}

O Transtorno do Déficit de Atenção com Hiperatividade (TDAH) tem origem multifatorial, integrando fatores neurobiológicos, ambientais e genéticos com múltiplos genes associados, sendo comumente revelado na infância, acompanhando o indivíduo por toda a sua vida (ROHDE; HALPERN, 2004), uma vez que seus sintomas podem comprometer a vida social, escolar e profissional, além da autoestima (CAPELLINI et al., 2007).

No diagnóstico clínico do TDAH leva-se em consideração todas as comorbidades do paciente, sendo caracterizado por sintomas de desatenção, inquietude e impulsividade, podendo ser classificado em três subtipos, o misto, predominantemente hiperativo e predominantemente desatento (AMERICAN PSYCHIATRIC ASSOCIATION, 2014). Neste sentido, o conhecimento e a informação são imprescindíveis para a melhoria da qualidade de vida e suporte aos portadores do TDAH, sendo que alguns países já iniciaram políticas públicas para promoção da assistência à saúde, priorizando sempre a proteção e a integridade do indivíduo em sociedade (COUTO; DUARTE; DELGADO, 2008).

$\mathrm{Na}$ análise molecular do TDAH, Mick e Farone (2008) associaram a forte relação do transtorno com os genes Dopamine Receptor D4 (DRD4), Dopamine Receptor D5 (DRD5), Dopamine Beta-Hydroxylase $(\mathrm{DBH})$, Synaptosome Associated Protein 25 (SNAP25), Solute Carrier Family 6 Member 4 (SLC6A4) e 5-Hydroxytryptamine Receptor 1B (HTR1B), e uma baixa relação com Carrier Family 6 Member 4 (SLC6A3). A partir da recorrência dos sintomas no TDAH, Topczewski (2014) sugere alterações nos neurotransmissores cerebrais, principalmente a noradrenalina, serotonina e dopamina.

A serotonina ou 5-hidroxitriptamina está amplamente distribuída em todo o sistema nervoso central, revelando-se essencial para o funcionamento de diversas regulações fisiológicas, como da emoção, o controle cognitivo, o processamento sensorial, a aprendizagem e memória (LIY-SALMERON; MENESES, 2007; MILLAN et al., 2008), sendo estes fatores relacionados diretamente ao TDAH, uma vez que essas atividades fisiológicas estão correlacionadas com os sintomas característicos do transtorno desatento (AMERICAN PSYCHIATRIC ASSOCIATION, 2014). Além disso, vários transtornos mentais ou comportamentais, como a esquizofrenia e a depressão, estão ligados à disfunção da expressão da serotonina (XIA et al., 2020).

A síntese da serotonina no organismo humano é iniciada a partir do precursor triptofano, o qual é convertido em 5hidroxitriptofano pela ação da enzima triptofano hidroxilase, seguida de uma descarboxilação, chegando ao produto final (Li et al., 2018) e se distribuindo por todo sistema nervoso central (RANG et al., 2016). Por outro lado, a neurotransmissão serotoninérgica é de extrema complexidade, devido aos diversos receptores nos quais a serotonina se liga. Sete classes de receptores de serotonina (5-HTR) já foram descritas, sendo elas: $5-\mathrm{HT} 1$ (1A, 1B, 1D, 1E e 1F), 5-HT2 (2A, 2B e 2C), 5-HT3, 5HT4, 5-HT5 (5A e 5B), 5-HT6 e 5-HT7 (ZIFA; FILLION, 1992). Por funcionarem como receptores, autorreceptores e também como heterorreceptores, os 5-HTR podem modular a liberação de dopamina influenciando os comportamentos mediados pelo neurotransmissor, sendo relevantes em indivíduos com TDAH (QUIST et al., 2003). Um exemplo disso é o fato de mutações no gene HTR1B resultarem em alterações na expressão e estrutura dos 5-HTR contribuindo para o desenvolvimento do transtorno (HAWI et al., 2002).

O receptor HTR1B possui papel essencial na regulação da síntese e liberação de serotonina, sendo que diversos polimorfismos no seu gene estão relacionados intimamente aos transtornos mentais e comportamentais (XIA et al., 2020). Estudos têm associado o gene HTR1B à desatenção e à hiperatividadeimpulsividade (BIDWELL et al., 2017), bem como ao comportamento agressivo (HAWI et al., 2002).

Ainda, a associação do polimorfismo de nucleotídeo único (SNP) C861G no HTR1B com o TDAH revelou a suscetibilidade gênica 
ao transtorno (ICKOWICZ et al., 2006). Isso é, ocorre uma transmissão preferencial e supertransmissão paterna do alelo 861G para a prole com TDAH (HAWI et al., 2002; ; QUIST et al., 2003; ICKOWICZ et al., 2006; ). No entanto, por ser improvável que este polimorfismo altere a estrutura do receptor, é possível que outra variante na sequência codificadora ou reguladora esteja em desequilíbrio de ligação com o C861G, podendo colaborar com o desenvolvimento do TDAH (HAWI et al., 2002). Assim, Quist et al. (2003) indicaram que os genes de receptores de serotonina, principalmente o HTR1B, podem ser importantes fatores de risco para $O$ desenvolvimento de TDAH.

Neste sentido, considerando a importância dos receptores de serotonina e sua relação com o TDAH, este estudo teve como objetivo analisar, a partir de ferramentas de biologia computacional, o perfil de expressão gênica e proteica de HTR1B, revelando suas características em Homo sapiens e em outros primatas não humanos.

\section{MATERIAL E MÉTODO}

Estudo exploratório e descritivo foi realizado baseando-se em revisão bibliográfica e no uso de ferramentas de biologia computacional para obtenção de dados sobre o TDAH e HTR1B (Figura 1).

Figura 1- Etapas metodológicas para caracterização genética e bioquímica do HTR1B.

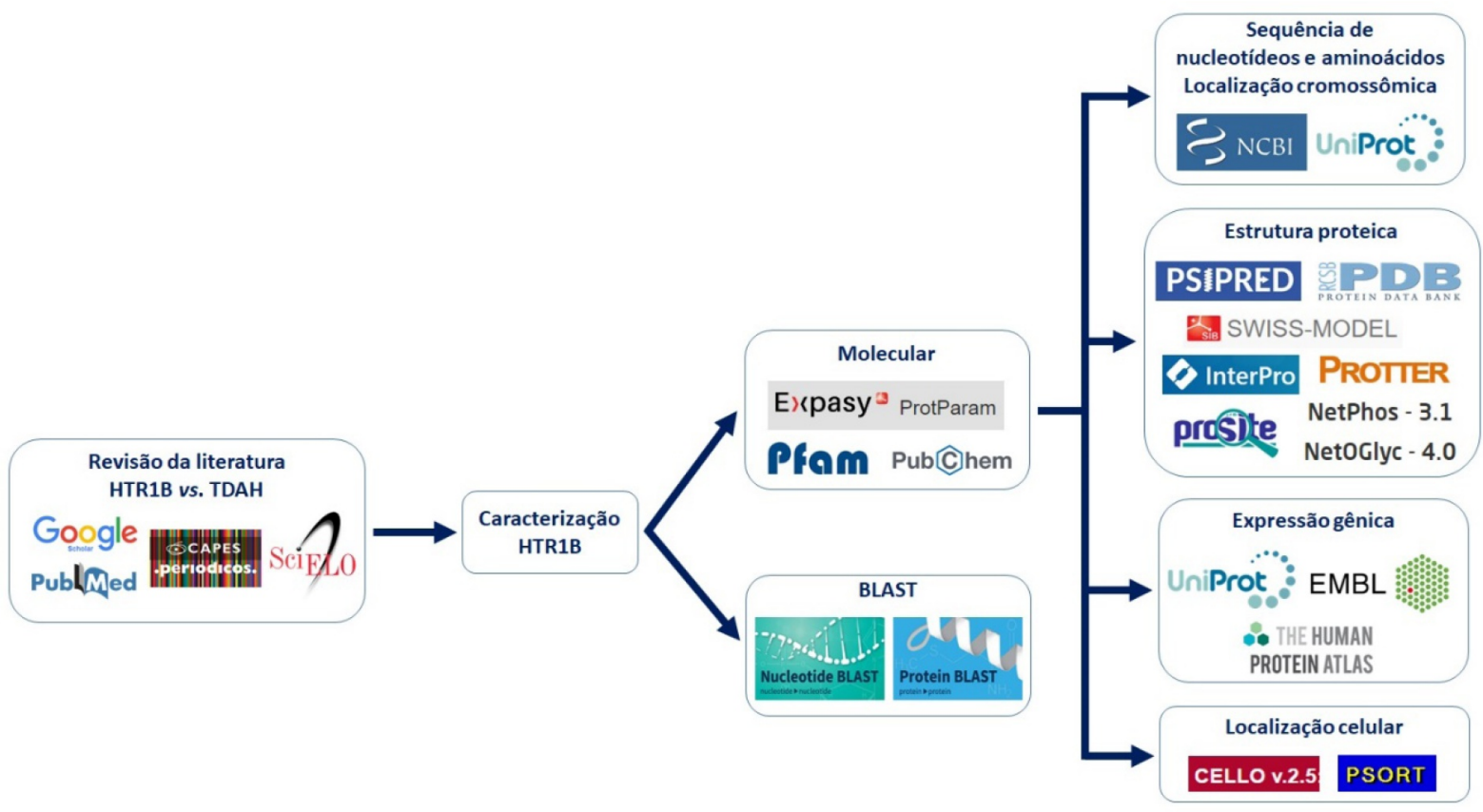

Fonte: Os autores.

A revisão da literatura foi realizada nas bases de dados Google Scholar, SciELO, PubMed e Periódicos Capes utilizando como entrada as seguintes palavras-chave: "TDAH", "transtorno de déficit de atenção com hiperatividade", "HTR1B", "receptor", "5hidroxitriptamina", "serotonina", "neurotransmissor" e "bioinformática", bem como seus correspondentes em inglês, além do termo AND para incorporar a busca, sem restrição de ano e idioma. As bibliografias foram consideradas válidas quando no formato de artigo original, artigo de revisão, tese de doutorado, dissertação de mestrado e trabalho de conclusão de curso.

A sequência de resíduos de nucleotídeos e de aminoácidos do HTR1B de Homo sapiens no formato FASTA foi obtida a partir do banco de dados NCBI - National Center of Biotechnology Information (https:/l www.ncbi.nlm.nih.gov/) e UniProtKB - UniProt Knowledgebase (https://www.uniprot.org/). 
As características moleculares foram reveladas consultando a ferramenta ProtParam (https://web.expasy.org/protparam/) no banco de dados Expasy, bem como as plataformas Pfam (http://pfam.xfam.org/) e PubChem (https://pubchem.ncbi.nlm.nih.gov/) para consulta de classe e família do HTR1B.

Por meio do PsiPred - Predict Secondary Structure (http://bioinf.cs.ucl.ac.uk/psipred/), a estrutura secundária foi predita, incluindo a composição de arranjos e polaridade dos aminoácidos. Entretanto, para fins de validação, a estrutura secundária do HTR1B também foi obtida no PDB - Protein DataBase (https://www.rcsb.org/) e confirmada no SwissModel (https://swissmodel.expasy.org/), o qual revelou também os domínios transmembrana, coincidindo com os resultados do Interpro (https://www.ebi.ac.uk/interpro/). A distribuição das regiões transmembranas nos domínios citoplasmáticos e não citoplasmáticos foi acessada a partir do Protter (https:// wlab.ethz.ch/protter/). Além disso, domínios e sítios ligantes foram inicialmente levantados pela ferramenta ScanProsite (https:// prosite.expasy.org/scanprosite) e validados pelas plataformas NetPhos 3.1 (https:// services.healthtech.dtu.dk/service.php?

NetPhos-3.1) e NeOGLyc/NetNGLyc (https:// services.healthtech.dtu.dk/service.php?

NetOGlyc-4.0).

A localização cromossômica do HTR1B foi obtida a partir do banco de dados NCBI e UniProtKB. As plataformas UniProtKB, EMBLEBI - European Molecular Biology Laboratory (https://www.ebi.ac.uk/) e The Human Protein Atlas (https://www.proteinatlas.org/) foram utilizadas para a descrição da localização de expressão gênica em diferentes tecidos e órgãos.

A plataforma CELLO: Subcellular Localization Predictive System (http:// cello.life.nctu.edu.tw/) e o software PSORT-B Prediction of Protein Sorting Signals and Localization Sites in Amino Acid Sequences (http://psort1.hgc.jp/form.html)

foram consultados para obtenção de informações sobre a localização celular de HTR1B, restringindo para organismos primatas.

A construção dos alinhamentos locais, a análise de identidade e grau de similaridade foram feitas utilizando a ferramenta BLAST Basic Local Alignment Search Tool (https:// blast.ncbi.nlm.nih.gov/Blast.cgi), selecionando a opção "Nucleotide>Nucleotide", e seguindo como "Nucleotide collection ( $\mathrm{nr} / \mathrm{nt}$ )" no tópico "Database"; e selecionando a opção "Protein>Protein", seguindo como "Nonredundant protein sequences ( $n r)$ " no tópico "Database". A título de comparação, em ambas as análises não ocorreu inserção de código no tópico "Organism" para que não houvesse exclusão de nenhuma espécie. Nesta análise, a identidade (\%) revelou a quantidade de matches entre as sequências e o valor estatístico (E-value) apareceu zerado em todas as espécies, considerando somente valor de identidade superior ou igual a $97 \%$.

\section{RESULTADOS E DISCUSSÃO}

A serotonina apresenta um papel essencial em diversas atividades fisiológicas, como a cognição, a atividade locomotora, regulação do sono, da dor e da agressão, inclusive atuando como neurotransmissor em comportamentos hiperativos e impulsivos presentes no TDAH (ICKOWICZ et al., 2006).

O gene HTR1B codifica o receptor 5hidroxitriptamina $1 \mathrm{~B}$ que desempenha importante papel no sistema serotoninérgico, estando amplamente ligado às atividades cerebrais e aos transtornos mentais e comportamentais (XIA et al., 2020). Apesar do nome oficial ser receptor de 5-hidroxitriptamina $1 \mathrm{~B}$, é também encontrado na literatura como serotonina acoplada à proteína G, receptor beta de serotonina 1D e receptor de serotonina $1 \mathrm{~B}$; da mesma maneira que há variações para as siglas, como 5-HT1B, HTR1D2, 5-HT-1B, 5HT1DB, 5-HT-1D-beta, S12 (NCBI, 2021).

Identificado pela primeira vez em 1992 por cinco grupos diferentes a partir do DNA genômico, o gene HTR1B foi detectado por homologia com o HTR1D humano. Estes estudos identificaram que o gene HTR1B não possuía íntrons (DEMCHYSHYN et al., 1992; HAMBLIN et al., 1992; MOCHIZUKI et al., 1992; WEINSHANK et al., 1992), estando localizado no cromossomo 6 (DEMCHYSHYN 
et al., 1992) em 6q13 (JIN et al., 1992). Além disso, o receptor possui características de um ligante à proteína G (HAMBLIN et al., 1992; JIN et al., 1992; MOCHIZUKI et al., 1992), codificando uma proteína de 390 aminoácidos (DEMCHYSHYN et al., 1992; HAMBLIN et al., 1992; MOCHIZUKI et al., 1992).

\subsection{ACHADOS BIOQUÍMICOS GENÉTICOS DE HTR1B VS. TDAH}

Vários estudos têm correlacionado a expressão do HTR1B com o TDAH nos mais diferentes métodos experimentais (HAWI et al., 2002; QUIST et al., 2003; ICKOWICZ et al., 2006; BIDWELL et al., 2017; XIA et al., 2020). Bidwell et al. (2017) associaram fortemente um locus deste gene com a desatenção e revelaram tendência de associação com hiperatividade-impulsividade. Da mesma forma, Hawi et al. (2002), Quist et al. (2003) e Xia et al. (2020) associaram o gene HTR1B com a hiperatividade e agressividade, enquanto Ickowicz et al. (2006) apontaram que a serotonina e seus genes possuem papel mediador nos sintomas do TDAH.

Esses dados são possivelmente explicados pela relação que a serotonina tem sobre a dopamina, a qual é o principal componente envolvido no TDAH (QUIST et al., 2003); isso é, os neurônios serotoninégicos regulam a liberação da dopamina e o disparo dos neurônios (ZENI, 2006). Assim, os efeitos do gene HTR1B sobre a dopamina interferem diretamente sobre os sintomas do TDAH, pois alterações no receptor podem causar desequilíbrio na relação serotonina-dopamina no cérebro (QUIST et al., 2003; GUIMARÃES, 2006). Por fim, Hawi et al. (2002) indicaram que mutações em HTR1B que afetem sua estrutura ou expressão estão relacionadas ao desenvolvimento do TDAH. A sequência de nucleotídeos (Tabela 1) e de resíduos de aminoácidos (Tabela 2) do HTR1B de Homo sapiens foi obtida no NCBI (2021).

\subsection{LOCALIZAÇÃO CROMOSSÔMICA DO GENE HTR1B E SUAS VARIANTES}

Apesar de Jin et al. (1992) terem descrito a localização do gene como $6 q 13$, atualmente já se sabe que a localização é $6 q 14.1$ (NCBI, 2021) (Figura 2), possuindo 2.568 nucleotídeos (Tabela 1).

Dados do UniProtKB (P28222) revelaram

Figura 2- Localização cromossômica do gene HTR1B, com destaque em caixa vermelha.

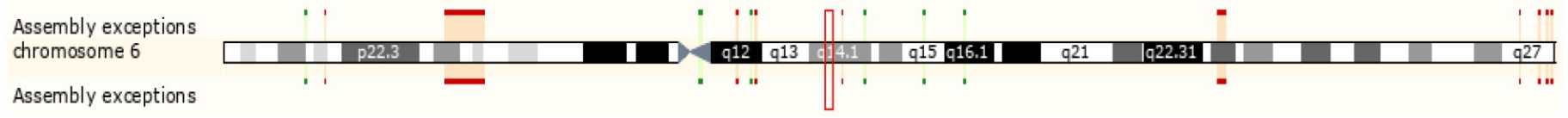

Fonte: ENSEMBL (2021).

quatro variantes dbSNP, sendo elas rs 130060 , rs130061, rs130063 e rs130064, indicando substituição dos aminoácidos fenilalanina por cisteína na posição 124 , fenilalanina por leucina na posição 219 , isoleucina por valina na posição 367 e glutamato por lisina na posição 374 (UNIPROTKB, 2021). Hawi et al. (2002); Quist et al. (2003); Ickowicz et al. (2006) e sugeriram suscetibilidade gênica ao TDAH ao observarem relação entre o SNP
C861G do gene HTR1B e esse transtorno, indicando a substituição do aminoácido fenilalanina por cisteína na posição 124 , além de duas substituições sinônimas e uma deleção na região flanqueadora 5', concordando com dados do UniProtKB (2021). 
Tabela 1- Características do gene HTR1B, incluindo códigos de acesso, nome de descrição e sequência de nucleotídeos no formato FASTA

\begin{tabular}{|c|c|c|}
\hline Código de acesso & Nome & Sequência de nucleotídeos \\
\hline $\begin{array}{l}\text { NCBI: } 3351 \\
\text { UniProtKB: P28222 }\end{array}$ & $\begin{array}{l}\text { 5-hydroxytryptamine } \\
\text { receptor } 1 B\end{array}$ & 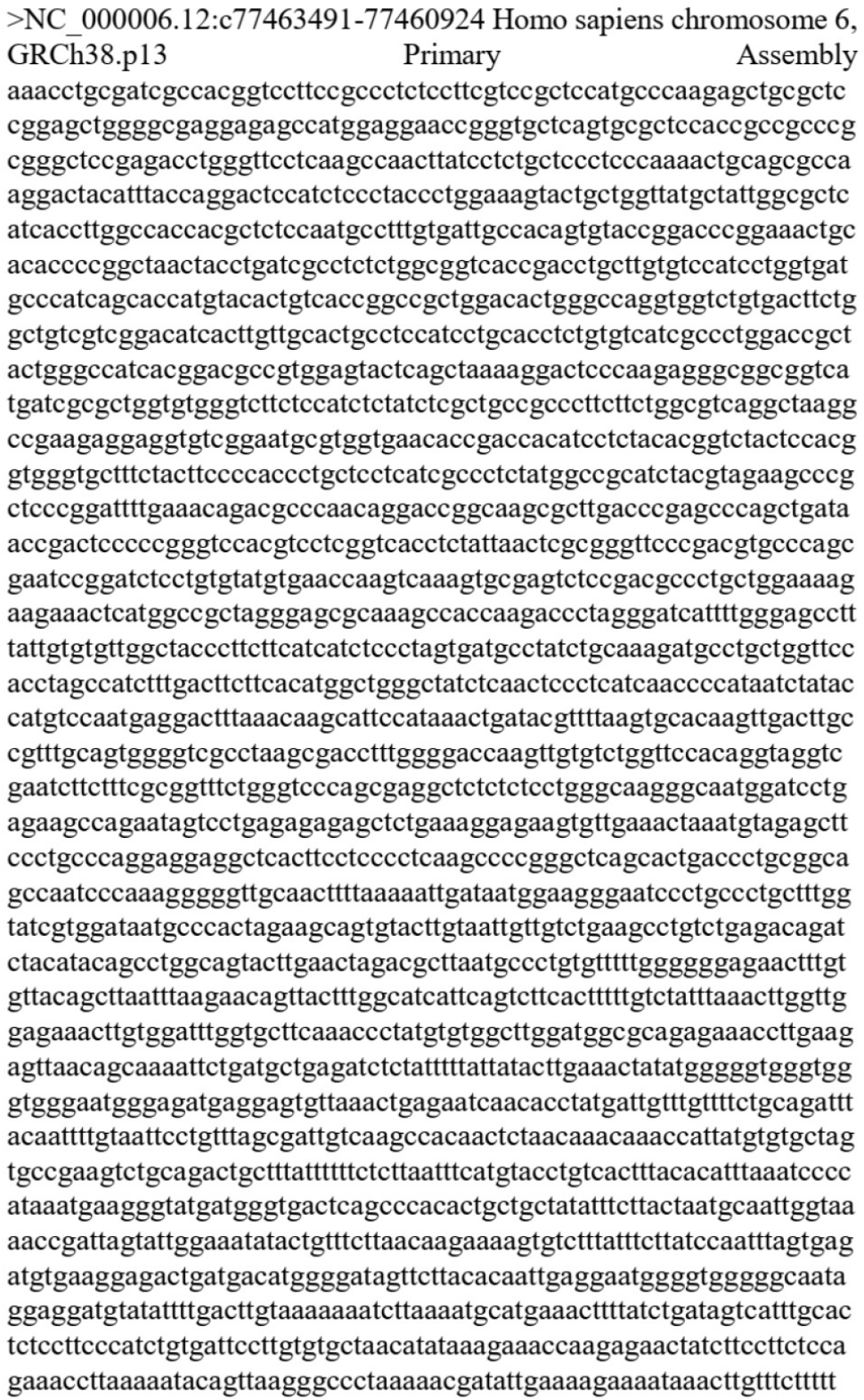 \\
\hline
\end{tabular}

Fonte: Os autores. Dados extraídos do NCBI.

3.3 CARACTERÍSTICAS BIOQUÍMICAS DA PROTEÍNA HTR1B

Para a proteína HTR1B em Homo sapiens encontrou-se apenas um depósito de sequência no NCBI e UniProtKB (até outubro/ $2021 \quad$ (Tabela 2). Segundo dados do PubChem e PFAM, o receptor expresso é uma proteína acoplada à proteína G (GPCR), pertencente à classe A Rhodopsin-like e subfamília A19. Quando a serotonina se liga ao seu receptor, ocorre uma mudança conformacional que dispara a sinalização via proteínas de ligação do nucleotídeo guanina (proteínas G) e modula a atividade de seus efetores, como a adenilato ciclase. A sinalização inibe a atividade da adenilato ciclase, enquanto os membros da família arrestina inibem a sinalização via proteínas $G$ e produzem a liberação de serotonina, dopamina e acetilcolina no cérebro, afetando assim a atividade neural. 
Tabela 2- Características do receptor HTR1B, incluindo códigos de acesso, nome de descrição e sequência de aminoácidos no formato FASTA

\begin{tabular}{|c|c|c|}
\hline Código de acesso & Nome & Sequência de aminoácidos \\
\hline $\begin{array}{l}\text { NCBI: }{ }^{N P} 000854 \\
\text { UniProtKB: } \mathrm{P} 28222\end{array}$ & $\begin{array}{l}\text { 5-hydroxytryptamine } \\
\text { receptor } 1 B\end{array}$ & $\begin{array}{l}\text { >NP_000854.1 5-hydroxytryptamine receptor } 1 \mathrm{~B} \text { [Homo } \\
\text { sapiens] } \\
\text { MEEPGAQCAPPPPAGSETWVPQANLSSAPSQNCSAKDYI } \\
\text { YQDSISLPWKVLLVMLLALITLATTLSNAFVIATVYRTRK } \\
\text { LHTPANYLIASLAVTDLLVSILVMPISTMYTVTGRWTLG } \\
\text { QVVCDFWLSSDITCCTASILHLCVIALDRYWAITDAVEYS } \\
\text { AKRTPKRAAVMIALVWVFSISISLPPFFWRQAKAEEEVSE } \\
\text { CVVNTDHILYTVYSTVGAFYFPTLLLIALYGRIYVEARSR } \\
\text { ILKQTPNRTGKRLTRAQLITDSPGSTSSVTSINSRVPDVPS } \\
\text { ESGSPVYVNQVKVRVSDALLEKKKLMAARERKATKTLG } \\
\text { IILGAFIVCWLFFIISLVMPICKDACWFHLAIFDFFTWLGY } \\
\text { LNSLINPIIYTMSNEDFKQAFHKLIRFKCTS }\end{array}$ \\
\hline
\end{tabular}

Fonte: Os autores. Dados extraídos do NCBI.

A sequência da proteína HTR1B em Homo sapiens no NCBI tem como código de acesso NP_000854 e 390 aminoácidos, massa molecular de 43,56 kDa e ponto isoelétrico de 8,96. A sequência de aminoácidos revelou a composição dos principais resíduos, sendo Leu
$(10,8 \%)$, Ala $(9,0 \%)$ e Ser $(9,0 \%)$ como os mais prevalentes, e Met $(2,1 \%)$ e His $(1,3 \%)$ como os menos frequentes, tendo $14 \mathrm{Asp}$ e $13 \mathrm{Glu}$ carregados negativamente e $18 \mathrm{Arg}$ e 18 Lys carregados positivamente (Tabela 3 ).

Tabela 3- Composição e frequência de aminoácidos da sequência primária de HTR1B

\begin{tabular}{cccc}
\hline Aminoácido & Abreviatura e sigla & Quantidade & Frequência \\
\hline Leucina & Leu (L) & 42 & $10,8 \%$ \\
Alanina & Ala (A) & 35 & $9,0 \%$ \\
Serina & Ser (S) & 35 & $9,0 \%$ \\
Valina & Val (V) & 32 & $8,2 \%$ \\
Isoleucina & Ile (I) & 31 & $7,9 \%$ \\
Treonina & Thr (T) & 31 & $7,9 \%$ \\
Prolina & Pro (P) & 22 & $5,6 \%$ \\
Lisina & Lys (K) & 18 & $4,6 \%$ \\
Arginina & Arg (R) & 18 & $4,6 \%$ \\
Fenilalanina & Phe (F) & 17 & $4,4 \%$ \\
Tirosina & Tyr (Y) & 15 & $3,8 \%$ \\
Aspartato & Asp (D) & 14 & $3,6 \%$ \\
Glutamato & Glu (E) & 13 & $3,3 \%$ \\
Glicina & Gly (G) & 12 & $3,1 \%$ \\
Asparagina & Asn (N) & 11 & $2,8 \%$ \\
Cisteína & Cys (C) & 11 & $2,8 \%$ \\
Glutamina & Gln (Q) & 10 & $2,6 \%$ \\
Triptofano & Trp (W) & 10 & $2,6 \%$ \\
Metionina & Met (M) & 8 & $2,1 \%$ \\
Histidina & His (H) & 5 & $1,3 \%$ \\
\hline
\end{tabular}

Fonte: Os autores. Dados extraídos do ProtParam.

Apesar da predição do PsiPred, a partir da sequência primária dos resíduos de aminoácidos do HRT1B, indicar a presença de dez arranjos alfa-hélice intercalados com curva-beta e um pequeno fragmento com conformação-beta, outros bancos de dados e softwares de análise de biologia computacional revelam estruturas secundárias diferentes para o receptor. A análise da estrutura secundária do HTR1B no PDB, com código de acesso
6G79 e nomeada como 5-hidroxitriptamina receptor $1 \mathrm{~B}$, indicou a presença e localização de oito arranjos alfa-hélice, porém demonstrou ter um comprimento de sequência menor comparado a de outros bancos de dados, possuindo 364 resíduos de aminoácidos (Figura 3). 
Figura 3- Arranjos da estrutura secundária do HTR1B revelada por microscopia eletrônica.

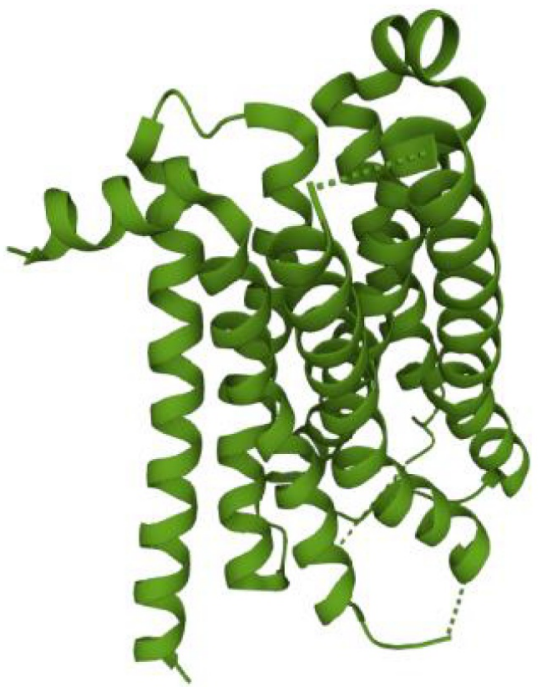

Fonte: RCSB PDB (2021).

Por outro lado, no Uniprot (P28222) a transmembrana citoplasmáticos e não estrutura secundária é revelada com apenas citoplasmáticos, bem como os sítios de treze arranjos de alfa-hélice, sem descrever a glicosilação presentes na estrutura proteica do presença de curva-beta que une os arranjos, o HTR1B (Figura 4), como as modificações pósque seria primordial nos conceitos bioquímicos.

Ainda na plataforma do Expasy, no SwissModel, há a predição da estrutura secundária concordando com o PDB (6G79), mas revelando sete arranjos alfa-hélice, sendo todos de domínio transmembrana. Esses dados foram validados pelo Interpro (IPR002147), no qual a estrutura secundária completa indica quatro domínios citoplasmáticos, quatro domínios não citoplasmáticos e sete domínios transmembrana.

Tendo como base a análise no Protter, foi possível ilustrar a localização dos domínios traducionais. Estas modificações são eventos críticos que alteram as propriedades da proteína causando diversos efeitos, como ampliação e regulação da função, alteração da atividade, localização e dobra/curva, assim como na interação com outras proteínas (MANN; JENSEN, 2003; SEO; LEE, 2004). Khoury; Baliban; Floudas (2011) destacam ainda a possibilidade de diferentes formas de modificação pós-traducional ocorrerem em conjunto, diferentemente das mutações que surgem apenas uma vez por posição. 
Figura 4- Predição da localização dos domínios transmembrana citoplasmáticos e não citoplasmáticos a partir do Protter

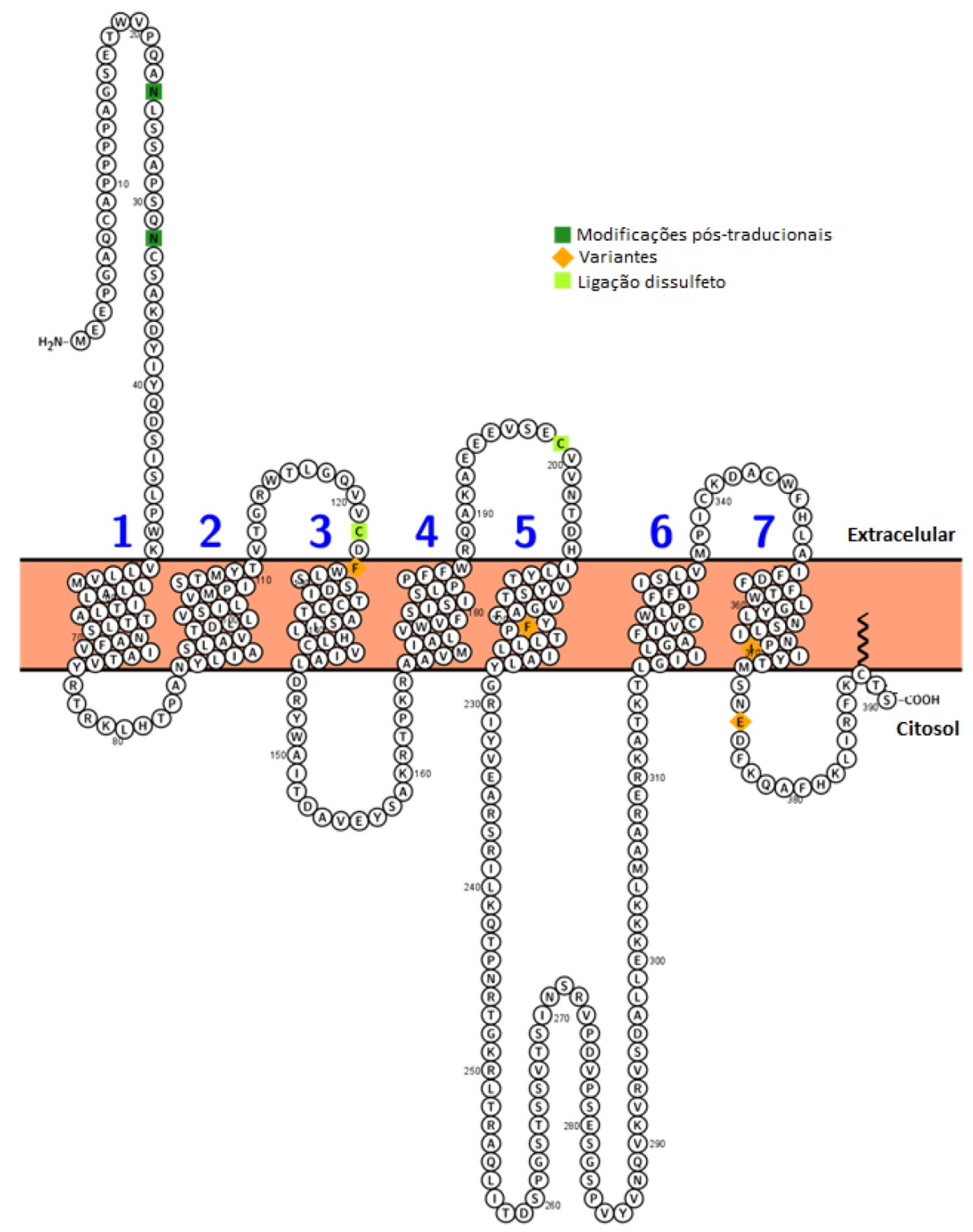

Fonte: Adaptada de Omasits et al. (2014).

Treze sítios foram revelados a partir de análise nos bancos de dados PROSITE, NeOGLyc/NetNGLyc e Glygen, como mostra o quadro 1, incluindo glicosilação, fosforilação, miristoilação e amidação. Apesar de existirem dois principais tipos de glicosilação, Oglicosilação e N-glicosilação (JAEKEN, 2010), os resultados indicam apenas sítios de $\mathrm{N}$ glicosilação na HTR1B, consistindo no processo de adição de um oligossacarídeo ao grupo amino da aspargina extracelular (CZUBA; HILLGREN; SWAAN, 2018), sendo doze alvos, sete resíduos de serina nas posições $16,25,26,27,30,34$ e 388 , dois resíduos de treonina 18 e 243 , e três resíduos de asparagina 24,32 e 245 .

Quanto à fosforilação foram identificados trinta e sete resíduos alvo, sendo vinte de serina nas posições $27,30,34,45,64,90,127$, 136, 158, 197, 258, 263, 265, 266 283, 295, $334,362,372$ e 389 e dezessete de treonina nas posições $63,73,77,82,107,110,112^{*}$, 116, 152, 162, 209, 213, 243, 247, 252, 313 e 315. Além disso, são alvos de fosforilação da proteína quinase dependente de AMPc e GMPCs os intervalos 249-252 e 310-313. Ainda, a sequência primária do HTR1B apresenta intervalos alvo para miristoilação (118-123, 262-123, 317-322) e amidação (247250). 
Quadro 1- Sítios de glicosilação, fosforilação, miristoilação e amidação do receptor HTR1B

\begin{tabular}{|l|c|}
\hline \multicolumn{1}{|c|}{ Sítios } & Resíduos de aminoácido alvo \\
\hline ASN_Glicosilação & $\begin{array}{c}\text { Ser16, Thr18, Asp24, Ser25, } \\
\text { Ser26, Ser27, Ser30, Asp32, } \\
\text { Ser34, Thr243, Asp245 e Ser388 }\end{array}$ \\
\hline Fosforilação da proteína quinase C (PKC) & $\begin{array}{c}\text { Ser34, Thr63, Thr73, Thr77*, } \\
\text { Thr110, Thr112*, Ser158, Thr162 } \\
\text { Thr209, Thr213, Thr247*, Ser263, } \\
\text { Ser266, Thr315 e Ser389 }\end{array}$ \\
\hline Fosforilação da caseína quinase II (CKII) & $\begin{array}{c}\text { Ser34, Ser127, Thr152, Ser197 e } \\
\text { Ser372 }\end{array}$ \\
\hline Fosforilação da proteína quinase dependente de cAMP e cGMP & $249-252$ e 310-313 \\
\hline Fosforilação da quinase dependente de ciclina (CDK) & Ser27, Ser45, Ser64, Ser258 e \\
Ser265
\end{tabular}

Fonte: Os autores. Dados extraídos do PROSITE, NeOGLyc/NetNGLyc e Glygen.

\subsection{EXPRESSÃO GÊNICA E PROTEICA DE HTR1B EM TECIDOS E ÓRGÃOS HUMANOS}

A expressão do gene HTR1B está descrita no córtex cerebral, corpo estriado, amígdala, medula, hipocampo, núcleo caudado e putâmen, enquanto a proteína é principalmente encontrada nas células do músculo liso da artéria cerebral (UNIPROTKB, 2021), mas também no rombencéfalo, lobo frontal cerebral, hipófise, diencéfalo e mesencéfalo (EMBL-EBI, 2021), e abundantemente expressa no músculo estriado (JIN et al., 1992). Dados obtidos no The Human Protein Atlas (2021) apontam expressão do HTR1B no cérebro, estômago e placenta, com destaque nas regiões do gânglio basal, córtex, ponte, medula e hipotálamo.

Apesar do córtex não possuir a maior expressão de HTR1B dentre as regiões do cérebro, essa é a mais afetada no TDAH (LIU et al., 2017). Liu et al. (2017) observaram padrão de afinamento cortical em pacientes com TDAH, com foco nas regiões frontal e temporal, as quais incluem áreas criticamente relacionadas aos mecanismos de atenção. As regiões temporal inferior esquerdo, orbitofrontal esquerdo e medial direito, além da frontal superior bilateral revelaram menor espessura cortical, indicando papel importante na patogênese do TDAH. Além disso, a conectividade funcional aumentada no córtex frontal superior obteve relação positiva com a hiperatividade e a impulsividade. Anormalidades em estruturas subcorticais, como o gânglio basal, região importante no controle da atenção, também têm sido observadas em estudos de imagem (HAWI et al., 2002).

\subsection{LOCALIZAÇÃO CELULAR DE} HTR1B

Dados levantados a partir do PSORT utilizando os resíduos de aminoácidos de HTR1B revelaram a localização celular na membrana plasmática (score 0,600) e no retículo endoplasmático (score 0,300 ). Por outro lado, dados levantados a partir da plataforma CELLO utilizando sequência de nucleotídeos indicaram a localização celular na membrana plasmática como região celular prevalente (score 4,928). Wang et al. (2013) 
relataram a localização do receptore HTR1B na membrana plasmática como um feixe canônico de sete a-hélices transmembranas, característico dos receptores pertencentes à família GPCR (SARKAR et al., 2020), como é o caso do receptor em estudo.

\subsection{IDENTIDADE DA SEQUÊNCIA DE HTR1B DE HUMANOS E OUTROS PRIMATAS}

O alinhamento da sequência de nucleotídeos (tabela 4) e de aminoácidos (tabela 5) de HTR1B de Homo sapiens com outras espécies, bem como a frequência de identidade (\%), os dados de E-value, os códigos de acesso e nomes das espécies, incluindo pares de base (bp) estão contidos nas Tabelas 4 e 5 . É possível observar similaridade com outros depósitos deste mesmo receptor de Homo sapiens, porém com menor quantidade de pares de bases. Além disso, os alinhamentos revelaram maior identidade entre a sequência de Homo sapiens e as de espécies de primatas, como Macaca silenus, $M$. nigra, $M$. sylvanus, $M$. nemestrina e M. mulatta, todos com $97,04 \%$, e mais de um depósito para as espécies $M$. sylvanus, $M$. nemestrina e M. mulatta.

Tabela 4- Identidade do alinhamento da sequência de nucleotídeos do receptor HTR1B de Homo sapiens com outras espécies (em \%)

\begin{tabular}{lccc}
\hline \multicolumn{1}{c}{ Espécie (nome popular) } & E-value & Identidade & Acesso \\
\hline Homo sapiens (homem) & 0.0 & 100 & NM_000863.3 \\
\hline Homo sapiens (homem) & 0.0 & 100 & M75128.1 \\
\hline Homo sapiens (homem) & 0.0 & 99,86 & M89478.1 \\
\hline Homo sapiens (homem) & 0.0 & 99,77 & D10995.1 \\
\hline Homo sapiens (homem) & 0.0 & 99,77 & AK290080.1 \\
\hline Homo sapiens (homem) & 0.0 & 99,75 & M83180.1 \\
\hline Homo sapiens (homem) & 0.0 & 99,72 & M84986.1 \\
\hline Macaca silenus (macaco-cauda-de-leão) & 0.0 & 97,04 & KC862501.1 \\
\hline Macaca nigra (macaco-de-crista das Celebes) & 0.0 & 97,04 & KC862500.1 \\
\hline Macaca sylvanus (macaco-de-gibraltar) & 0.0 & 97,04 & KC862493.1 \\
\hline Macaca nemestrina (macaco-de-cauda-de-porco) & 0.0 & 97,04 & KC862487.1 \\
\hline Macaca mulatta (macaco-rhesus) & 0.0 & 97,04 & KC862456.1 \\
\hline Macaca mulatta (macaco-rhesus) & 0.0 & 97,04 & KC862465.1 \\
\hline
\end{tabular}

Fonte: Os autores. Dados obtidos no Blastn. 
Anbazhagan et al. (2010) relataram homologia entre os receptores de serotonina de humanos e primatas, com um total de 32 resíduos de aminoácidos idênticos entre as duas sequências. Além disso, o chimpanzé possui $100 \%$ de identidade de HTR1B, HTR1F e HTR7 quando comparado com a sequência de humanos. Ainda, os autores indicaram que humanos e outros primatas não humanos apresentam diferenças em certos parâmetros, como o tamanho do cérebro, padrões e densidade de expressão gênica, modificações no RNA e interações gene-ambiente. Assim, apesar do alto nível de conservação do $H T R 1 B$, isso não resulta diretamente que esse gene possui função semelhante entre as espécies analisadas.

Tabela 5- Identidade do alinhamento da sequência de aminoácidos do receptor HTR1B de Homo sapiens com outras espécies (em \%)

\begin{tabular}{|c|c|c|c|}
\hline Espécie (nome popular) & E-value & Identidade & Acesso \\
\hline Homo sapiens (homem) & 0.0 & 100,00 & NP_000854.1 \\
\hline Gorilla gorilla gorilla (gorila do ocidente) & 0.0 & 99,74 & XP_004044362.2 \\
\hline Homo sapiens (homem) & 0.0 & 99,74 & BAF82769.1 \\
\hline Nomascus leucogenys (gibão-de-bochechas-brancas) & 0.0 & 99,23 & XP_003271184.1 \\
\hline Gorilla gorilla gorilla (gibão-de-bochechas-brancas) & 0.0 & 99,49 & Q9N2B7.1 \\
\hline Pongo abelii (Orangotango-de-sumatra) & 0.0 & 99,23 & XP_024104495.1 \\
\hline Rhinopithecus roxellana (macaco dourado) & 0.0 & 98,46 & XP_010364919.1 \\
\hline Hylobates moloch (gibão prateado) & 0.0 & 98,72 & XP_032020632.1 \\
\hline Piliocolobus tephrosceles (...) & 0.0 & 98,46 & XP_023078874.1 \\
\hline Macaca mulatta (macaco rhesus) & 0.0 & 97,95 & AGN73566.1 \\
\hline Macaca fuscata (macaco japonês) & 0.0 & 97,95 & AGN73542.1 \\
\hline Macaca fuscata (macaco japonês) & 0.0 & 97,95 & AGN73540.1 \\
\hline Macaca fuscata (macaco japonês) & 0.0 & 97,95 & AGN73543.1 \\
\hline Trachypithecus francoisi (Langur de françois) & 0.0 & 97,69 & XP_033091488.1 \\
\hline Theropithecus gelada (babuíno gelada) & 0.0 & 97,95 & XP_025239549.1 \\
\hline Macaca nemestrina (macaco de cauda de porco do sul) & 0.0 & 97,95 & AGN73583.1 \\
\hline Macaca fuscata (macaco japonês) & 0.0 & 97,69 & AGN73547.1 \\
\hline Papio anubis (babuíno anúbis) & 0.0 & 97,69 & XP_003897874.2 \\
\hline
\end{tabular}

Fonte: Os autores. Dados obtidos no Blastp. 
Além disso, estudos revelam que o HTR1B de Homo sapiens possui homologia com a sequência de resíduos de aminoácidos desse receptor em ratos (HAMBLIN et al., 1992; MOCHIZUKI et al., 1992) e também com o receptor 5-HT1D de cães e humanos (DEMCHYSHYN et al., 1992).

\section{CONCLUSÃO}

Dados levantados a partir da revisão de literatura e utilizando diferentes ferramentas de biologia computacional possibilitaram descrever características sobre a função e estrutura bioquímica e gênica do HTR1B e sua relação com o TDAH.

O gene $H T R 1 B$ não possui íntrons, está localizado em $6 q 14.1$, possui 2.568 nucleotídeos e codifica o receptor 5hidroxitriptamina 1B, o qual é traduzido em 390 resíduos de aminoácidos, compondo uma estrutura proteica localizada prevalentemente na membrana plasmática, com sete a-hélices transmembranares.

Apresentando modificações pós-traducionais, com destaque aos sítios de glicosilação, fosforilação, amidação e miristoilação, tem sua estrutura alterada, influenciando sua funcionalidade. O receptor HTR1B desempenha importante papel no sistema da serotonina, atuando como modulador envolvido em atividades cerebrais, bem como nos transtornos mentais $\mathrm{e}$ comportamentais. A expressão gênica e proteica de HTR1B está descrita em diversas regiões do corpo humano, incluindo o cérebro com destaque ao córtex cerebral, região mais afetada no TDAH.

A associação de HTR1B com o TDAH é sustentada pela relação da expressão gênica com os sintomas padrão do transtorno, a desatenção e a hiperatividade-impulsividade, além da correlação observada entre o polimorfismo de nucleotídeo único C861G do gene com tais sintomas. Assim, mutações no gene HTR1B que alterem sua estrutura ou expressão podem contribuir para o desenvolvimento do TDAH.

Por fim, a análise da identidade de HTR1B de $H$. sapiens comparada a outros organismos revela $100 \%$ de identidade com chimpanzés. No entanto, a ausência de evidências deixa dúvidas se o gene e a proteína possuem função semelhante nessas espécies.

Dada a importância do TDAH para os indivíduos acometidos por este transtorno e os prejuízos adquiridos, é importante a continuidade de estudos que o relacione com a expressão de HTR1B visando descobertas que contribuam para o seu diagnóstico, tratamento e até prevenção.

\section{CONFLITOS DE INTERESSES}

Não há conflito de interesse.

\section{REFERÊNCIAS}

AMERICAN

PSYCHIATRIC ASSOCIATION. Manual diagnóstico e estatístico de transtornos mentais. 5. ed. Porto Alegre: Artmed. 948 p. 2014.

ANBAZHAGAN, P.; PURUSHOTTAM, M.; KUMAR, H.B.K.; MUKHERJEE, O.; JAIN, S.; SOWDHAMINI, R. Phylogenetic analysis and selection pressures of $5-\mathrm{HT}$ receptors in human and non-human primates: receptor of an ancient neurotransmitter. Journal of Biomolecular Structure and Dynamics, v.27, n.5, p.581-598, 2010. DOI: http://dx.doi.org/ 10.1080/07391102.2010.10508573.

BIDWELL, L.C.; GRAY, J.C.; WEAFER, J.; PALMER, A.A.; WIT, H.; MACKILLOP, J. Genetic influences on ADHD symptom dimensions: examination of a priori candidates, gene-based tests, genome-wide variation, and SNP heritability. American Journal of Medical Genetics, Part B: Neuropsychiatric Genetics, v.174, n.4, p.458-466, 2017. DOI: http:// dx.doi.org/10.1002/ajmg.b.32535.

CAPELLINI, S.A.; FERREIRA, T.L.; SALGADO, C.A.; CIASCA, S.M. Desempenho de escolares bons leitores, com dislexia e com transtorno do déficit de atenção e hiperatividade em nomeação automática rápida. Revista da Sociedade Brasileira de Fonoaudiologia, v.12, n.2, p.114-119, 2007. 
DOI: http://dx.doi.org/10.1590/s151680342007000200008.

COUTO, M.C.V.; DUARTE, C.S.; DELGADO, P.G.G. A saúde mental infantil na saúde pública brasileira: situação atual $\mathrm{e}$ desafios. Revista Brasileira de Psiquiatria, v.30, n.4, p.390-398, 2008. DOI: http:// dx.doi.org/10.1590/s151644462008000400015 .

CZUBA, L.C.; HILLGREN, K.M.; SWAAN, P.W. Post-translational modifications of transporters. Pharmacology \& Therapeutics, v.192, p.88-99, 2018. DOI: http://dx.doi.org/ 10.1016/j.pharmthera.2018.06.013.

DEMCHYSHYN, L.; SUNAHARA, R.K.; MILLER, K.; TEITLER, M.; HOFFMAN, B.J.; KENNEDY, J.L.; SEEMAN, P.; VAN TOL, H.H.; NIZNIK, H.B. A human serotonin 1D receptor variant (5HT1D beta) encoded by an intron less gene on chromosome 6 . Proceedings of the National Academy of Sciences, v.89, n.12, p.5522-5526, 1992. DOI: http://dx.doi.org/ 10.1073/pnas.89.12.5522.

EMBL-EBI, European Molecular Biology Laboratory - European Bioinformatics Institute. Gene \& protein summary for HTR1B. 2021. Disponível em: https://www.ebi.ac.uk/ebisearch/ s4/summary/molecular?

tab=expression\&term=htr1b\&spine=molecular \& classification=9606\&tid=nameOrgENSG00000 135312. Acesso em: 29 mar. 2021.

ENSEMBL. Cromossomo 6: 77.460.92477.463.491. 2021. Disponível em: https:// www.ensembl.org/Homo_sapiens/Location/

View?

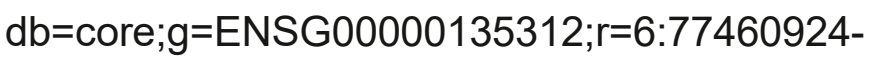
$77463491 ; \mathrm{t}=\mathrm{ENST} 00000369947$. Acesso em: 11 mar. 2021.

GUIMARÃES, A.P.M. Estudo de associação com genes candidatos do sistema serotoninérgico em crianças afetadas com o Transtorno de Déficit de Atenção e Hiperatividade (TDAH). [dissertação de mestrado]. Porto Alegre: Universidade Federal do Rio Grande do Sul; 2006.

HAMBLIN, M.W.; METCALF, M.A.; MCGUFFIN, R.W.; KARPELLS, S. Molecular cloning and functional characterization of a human 5-HT1B serotonin receptor: a homologue of the rat 5-HT1B receptor with 5HT1D-like pharmacological specificity. Biochemical and Biophysical Research Communications, v.184, n.2, p.752-759, 1992. DOI: http://dx.doi.org/10.1016/0006291x(92)90654-4.

HAWI, Z.; DRING, M.; KIRLEY, A.; FOLEY, D; KENT, L.; CRADDOCK, N.; ASHERSON, P.; CURRAN, S.; GOULD, A.; RICHARDS, S.; LAWSON, D.; PAY, H.; TURIC, D.; LANGLEY, K.; OWEN, M.; O'DONOVAN, M.; THAPAR, A.; FITZGERALD, M.; GILL, M. Serotonergic system and attention deficit hyperactivity disorder (ADHD): a potential susceptibility locus at the 5-HT1B receptor gene in 273 nuclear families from a multi-centre sample. Molecular Psychiatry, v.7, n.7, p.718725, 2002. DOI: http://dx.doi.org/10.1038/ sj.mp.4001048.

ICKOWICZ, A.; FENG, Y.; WIGG, K.; QUIST, J.; PATHARE, T.; ROBERTS, W.; MALONE, M.; SCHACHAR, R.; TANNOCK, R.; KENNEDY, J.L.; BARR, C.L. The serotonin receptor HTR1B: gene polymorphisms in attention deficit hyperactivity disorder. American Journal of Medical Genetics, Part B: Neuropsychiatric Genetics, v.144, n.1, p.121-125, 2006. DOI: http://dx.doi.org/10.1002/ ajmg.b.30398.

JAEKEN, J. Congenital disorders of glycosylation. Annals of the New York Academy of Sciences, v.1214, n.1, p.190198, 2010. DOI: http://dx.doi.org/10.1111/ j.1749-6632.2010.05840.x

JIN, H.; OKSENBERG, D.; ASHKENAZI, A.; PEROUTKA, S.J.; DUNCAN, A.M.; ROZMAHEL, R.; YANG, Y.; MENGOD, G.; PALACIOS, J.M.; O'DOWD, B.F. Characterization of the human 5hydroxytryptamine1B receptor. Journal of 
Biological Chemistry, v.267, n. 9, p.57355738, 1992. DOI: http://dx.doi.org/10.1016/ s0021-9258(18)42612-9.

KHOURY, G.A.; BALIBAN, R.C.; FLOUDAS, C.A. Proteome-wide posttranslational modification statistics: frequency analysis and curation of the swiss-prot database. Scientific Reports, v.1, n.90, p.1-5, 2011. DOI: http://dx.doi.org/10.1038/srep00090.

LI, Y.; LV, Y.; BIAN, C.; YOU, X.; DENG, L.; SHI, Q. A comparative genomic survey provides novel insights into molecular evolution of I-aromatic amino acid decarboxylase in vertebrates. Molecules v.23, n.4, 917(p.1-16), 2018. DOI: https://doi.org/10.3390/ molecules23040917.

LIU, T.; CHEN, Y.; LI, C.; LI, Y.; WANG, J. Altered brain structural networks in attention deficit/hyperactivity disorder children revealed by cortical thickness. Oncotarget, v.8, n.27, p.44785-44799, 2017. DOI: http://dx.doi.org/ 10.18632/oncotarget.14734.

LIY-SALMERON, G; MENESES, A. Role of 5-HT1-7 receptors in short - and long - term memory for an autoshaping task: intrahippocampal manipulations. Brain Research, v.1147, p.140-147, 2007. DOI: http:// dx.doi.org/10.1016/j.brainres.2007.02.007.

MANN, M.; JENSEN, O.N. Proteomic analysis of post-translational modifications. Nature Biotechnology, v.21, p.255-261, 2003. DOI: http://dx.doi.org/10.1038/nbt0303-255.

MICK, E.; FARAONE, S.V. Genetics of attention deficit hyperactivity disorder. Child and Adolescent Psychiatric Clinics of North America, v.17, n.2, p.261-284, 2008. DOI: http://dx.doi.org/10.1016/j.chc.2007.11.011.

MILLAN, M; MARIN, P; BOCKAERT, J; MANNOURYLACOUR, C. Signaling at Gprotein-coupled serotonin receptors: recent advances and future research directions. Trends in Pharmacological Sciences, v.29, n.9, p.454-464, 2008. DOI: http://dx.doi.org/ 10.1016/j.tips.2008.06.007.

MOCHIZUKI, D.; YUYAMA, Y.; TSUJITA, R.; KOMAKI, H.; SAGAI, H. Cloning and expression of the human 5-HT1B-type receptor gene. Biochemical and Biophysical Research Communications, v.185, n.2, p.517-523, 1992. DOI: $\quad$ http://dx.doi.org/10.1016/0006291x(92)91655-a.

NCBI, National Center of Biotechnology Information. HTR1B 5-hydroxytryptamine receptor 1B [Homo sapiens (human)]. 2021. Disponível em: https://www.ncbi.nlm.nih.gov/ gene/3351. Acesso em: 08 mar. 2021.

OMASITS, U.; AHRENS, C.H.; MÜLLER, S.; WOLLSCHEID, B. Protter: interactive protein feature visualization and integration with experimental proteomic data. Bioinformatics, v.30, n.6, p.884-886, 2014. DOI: http:// dx.doi.org/10.1093/bioinformatics/btt607.

QUIST, J.F.; BARR, C.L.; SCHACHAR, R.; ROBERTS, W.; MALONE, M.; TANNOCK, R.; BASILE, V.S.; BEITCHMAN, J.; KENNEDY, J.L. The serotonin 5-HT1B receptor gene and attention deficit hyperactivity disorder. Molecular Psychiatry, v.8, n.1, p.98-102, 2003. DOI: http://dx.doi.org/10.1038/sj.mp.4001244.

RANG, H.P.; RITTER, J.M.; FLOWER R.J.; HENDERSON G. Farmacologia. 8. ed. London: Elsevier; 784 p. 2016.

RCSB PDB, Protein Data Bank. 5-HT1B receptor. 2021. Disponível em: https:// www.rcsb.org/structure/6G79. Acesso em: 8 junho 2021.

ROHDE, L.A.; HALPERN, R. Transtorno de déficit de atenção/hiperatividade: atualização. Jornal de Pediatria, v.80, n.2, 2004. DOI: http://dx.doi.org/10.1590/S002175572004000300009 .

SARKAR, P.; MOZUMDER, S.; BEJ, A.; MUKHERJEE, S.; SENGUPTA, J.; CHATTOPADHYAY, A. Structure, dynamics and lipid interactions of serotonin receptors: 
excitements and challenges. Biophysical Reviews, v.13, n.2021, p.101-122, 2020. DOI: http://dx.doi.org/10.1007/s12551-020-00772-8.

SEO, J.; LEE, K.J. Post-translational modifications and their biological functions: proteomic analysis and systematic approaches. Journal of Biochemistry and Molecular Biology, v.37, n.1, p.35-44, 2004. DOI: http:// dx.doi.org/10.5483/bmbrep.2004.37.1.035.

THE HUMAN PROTEIN ATLAS. HTR1B. 2021. Disponível em: https:// www.proteinatlas.org/ENSG00000135312HTR1B/. Acesso em: 05 abr. 2021.

TOPCZEWSKI, A. Attention deficit and hyperactivity disorder: a therapeutic option. Einstein (São Paulo), v.12, n.3, p.310-313, 2014. DOI: http://dx.doi.org/10.1590/s1679$45082014 a 02925$.

UNIPROTKB, UniProt Knowledgebase. P28222 (5HT1B_HUMAN). 2021. Disponível em: https://www.uniprot.org/uniprot/P28222. Acesso em: 13 mar. 2021.

WANG, C.; JIANG, Y.; MA, J.; WU, H.; WACKER, D.; KATRITCH, V.; HAN, G.W.; LIU, W.; HUANG, X.P.; VARDY, E.; MCCORVY, J.D.; GAO, X.; ZHOU, X.E. MELCHER, K.; ZHANG, C.; BAI, F.; YANG, H.; YANG, L.; JIANG, H.; ROTH, B.L.; CHEREZOV, V.; STEVENS, R.C.; XU, H.E. Structural basis for molecular recognition at serotonin receptors. Science, v.340, n.6132, p.610-614, 2013. DOI: http://dx.doi.org/10.1126/science.1232807.

WEINSHANK, R.L.; ZGOMBICK, J.M.; MACCHI, M.J.; BRANCHEK, T.A.; HARTIG, P. R. Human serotonin 1D receptor is encoded by a subfamily of two distinct genes: 5-HT1D alpha and 5-HT1D beta. Proceedings of the National Academy of Sciences, v.89, n.8, p.3630-3634, 1992. DOI: http://dx.doi.org/ 10.1073/pnas.89.8.3630.

XIA, X.; DING, M.; XUAN, J.; XING, J.; YAO, J.; WU, X.; WANG, B. Functional polymorphisms and transcriptional analysis in the $5^{\prime}$ region of the human serotonin receptor 1B gene (HTR1B) and their associations with psychiatric disorders. BMC Psychiatry, v.20, n.499, p.1-10, 2020. DOI: http://dx.doi.org/ 10.1186/s12888-020-02906-4.

ZENI, C.P. Associação entre resposta clínica e eventos adversos ao metilfenidato e genes dopaminérgicos e serotoninérgicos em crianças e adolescentes com Transtorno de Déficit de Atenção/Hiperatividade. [dissertação de mestrado]. Porto Alegre: Universidade Federal do Rio Grande do Sul; 2006.

ZIFA, E.; FILLION, G. 5Hydroxytryptamine receptors.

Pharmacological Reviews, v.44, n.3, p.401458, 1992. 